\title{
Providing Stroke Expertise across India
}

\author{
Richard I. Lindley ${ }^{1, \odot}$ \\ ${ }^{1}$ Sydney Medical School, Westmead Applied Research Centre, \\ University of Sydney, New South Wales, Australia
}

J Neurosci Rural Pract 2021;12:226-227.

The vast majority of people in India live in a region with no stroke units, and no neurological expertise. ${ }^{1}$ Yet, stroke unit care is one of the most effective treatments for stroke, and provides the necessary infrastructure on which to build capacity for medical and neuro-intervention. ${ }^{2}$ Some acute stroke treatments are very cheap, and potentially available without expensive facilities, e.g., immediate aspirin for acute ischemic stroke and blood pressure lowering for hemorrhagic stroke. ${ }^{3,4}$ How should health care planners start to build stroke unit capacity in India. The article by John et al provides some new important data. ${ }^{5}$ These authors performed a before and after study of an implementation of a physician-based stroke unit model in a remote hospital in North East India.

Key components of the intervention included a stroke expert who was willing to provide time for mentoring and training, and identification of a local champion-a physician, who in a "train the trainer" model, helped educate the local team in basic stroke unit care. In this case, the local team includes the doctors, nurses, physiotherapist, and occupational therapist. The stroke unit care items were classed under "monitoring," "acute management," "team working," and "discharge planning" and, as is the case with many important health service interventions, it consisted of doing many simple tasks comprehensively. ${ }^{6}$

Their results were important. Although the study was too small to reliably estimate differences in functional outcome their processes of care clearly improved, particularly in swallow screening, use of antithrombotic therapy, and use of electrocardiograms to identify atrial fibrillation. Mobility assessment improved and every patient, post intervention, was discussed at a multidisciplinary meeting.

Challenges in rolling out such a model across India include the lack of sufficient numbers of Indian stroke experts to provide the required mentorship and training, but this is not a problem limited to India, with stroke expertise lacking in both high- and low-income countries. ${ }^{7,8}$ The self-nomination of a local physician willing to take on this role, and extend support in the local hospital, will also be a key limiting factor. Time and time again, the key to health service behavioral change is a local champion, and such champions can influence their local management. ${ }^{9}$ The results from the Tezpur study demonstrating a statistical decrease in hospital length of stay will be of particular interest to health providers with limited hospital beds. I strongly encourage all those in hospitals without stroke units to consider rolling out this model. But life is never that simple and next steps should also include implementation research to explore the best local incentives to attract physicians who are willing to take on stroke unit development, and explore different models of mentorship and roll out. Global funding opportunities should be sought to fund such important implementation research. ${ }^{10}$

One positive aspect of the current COVID-19 pandemic has been the enormous uptake of technology in medicine with videoconferencing becoming routine, and this, together with digital technology support with smartphones and smartphone applications could be explored to expand the basic stroke unit model as exemplified by the Tezpur model.

Once basic stroke units are established, treatment options can be advanced according to the local resources, such as consideration of thrombolysis and possible pathways to neurointervention (more feasible in areas near large urban centers). Given how common stroke has become (the main cause of death in some areas of India ${ }^{11}$ ) the next priority would be developing an Indian model of stroke rehabilitation following discharge from the stroke unit. Unfortunately, several low-cost models of care have not been shown to be beneficial (such as family-led rehabilitation, or nurse-led rehabilitation). ${ }^{12,13}$ Centre-based stroke support and rehabilitation may well be the best model to evaluate with some promising data from Africa on such a service. ${ }^{14}$

Stroke will remain a leading cause of premature death and disability for decades and the Tezpur model of basic stroke unit care provides a key example of cascading expertise to the population. Efforts to roll out this model should be a priority.

\author{
Address for correspondence Richard \\ I. Lindley, MD, Sydney Medical School, \\ Westmead Applied Research Centre, \\ University of Sydney, New South \\ Wales 2006, Australia \\ (e-mail: Richard.lindley@sydney.edu.au).
}

DOI https://doi.org/ $10.1055 / \mathrm{s}-0041-1726664$ ISSN 0976-3147 (c) 2021. Association for Helping Neurosurgical Sick People.

This is an open access article published by Thieme under the terms of the Creative Commons Attribution-NonDerivative-NonCommercial-License, permitting copying and reproduction so long as the original work is given appropriate credit. Contents may not be used for commercial purposes, or adapted, remixed, transformed or built upon. (https://creativecommons.org/licenses/by-nc-nd/4.0/).

Thieme Medical and Scientific Publishers Pvt. Ltd. A-12, 2nd Floor, Sector 2, Noida-201301 UP, India 


\section{Conflict of Interest}

R.I.L. reports his extensive collaboration in India and currently has a project based here.

\section{References}

1 Ganapathy K. Distribution of neurologists and neurosurgeons in India and its relevance to the adoption of telemedicine. Neurol India 2015;63(2):142-154

2 Langhorne P, de Villiers L, Pandian JD. Applicability of stroke-unit care to low-income and middle-income countries. Lancet Neurol 2012;11(4):341-348

3 Sandercock P, Gubitz G, Foley P, Counsell C. Antiplatelet therapy for acute ischaemic stroke. Cochrane Database Syst Rev 2003;(2):CD000029

4 Anderson CS, Heeley E, Huang Y, et al; INTERACT2 Investigators. Rapid blood-pressure lowering in patients with acute intracerebral hemorrhage. N Engl J Med 2013;368(25):2355-2365

5 John L, William A, Dawar D, et al. Implementation of a physician-based stroke unit in a remote hospital of North-East India-Tezpur model. J Neurosci Rural Pract 2021;12(2):356-361

6 Lindley RI. Stroke prevention in the very elderly. Stroke 2018;49(3):796-802
7 Mehndiratta MM, Singhal AB, Chaturvedi S, Sivakumar MR, Moonis M. Meeting the challenges of stroke in India. Neurology 2013;80(24):2246-2247

8 Kenton EJ, Culebras A, Fayad PB, et al; AAN Vascular Neurology Stroke Practice Resources Workgroup. Impact of stroke call on the stroke neurology workforce in the United States: possible challenges and opportunities. J Stroke Cerebrovasc Dis 2018;27(7):2019-2025

9 Miech EJ, Rattray NA, Flanagan ME, Damschroder L, Schmid AA, Damush TM. Inside help: an integrative review of champions in healthcare-related implementation. SAGE Open Med 2018;6:2050312118773261

10 Pandian JD, Liu H, Gandhi DB, Lindley RI. Clinical stroke research in resource limited settings: tips and hints. Int J Stroke 2018;13(2):129-137

11 Kalkonde YV, Deshmukh MD, Sahane V, et al. Stroke is the leading cause of death in rural Gadchiroli, India: a prospective community-based study. Stroke 2015;46(7):1764-1768

12 Zhou B, Zhang J, Zhao Y, et al. Caregiver-delivered stroke rehabilitation in rural China. Stroke 2019;50(7):1825-1830

13 ATTEND Collaborative Group. Family-led rehabilitation after stroke in India (ATTEND): a randomised controlled trial. Lancet 2017;390(10094):588-599

14 Melifonwu R. Clinical stroke research in resource limited settings: tips and hints. Int J Stroke 2019;14(5):NP13-NP14 